\title{
How to control a reverse logistics system when used items return with diminishing quality
}

DOI:

10.1007/978-3-319-89920-6_52

\section{Document Version}

Accepted author manuscript

Link to publication record in Manchester Research Explorer

\section{Citation for published version (APA):}

Dobos, I., Pishchulov, G., \& Gössinger, R. (2018). How to control a reverse logistics system when used items return with diminishing quality. In N. Kliewer, J. F. Ehmke, \& R. Borndörfer (Eds.), Operations Research Proceedings 2017 : Selected Papers of the Annual International Conference of the German Operations Research Society (GOR), Freie Universiät Berlin, Germany, September 6-8, 2017 (pp. 387-393). (Operations Research Proceedings). Springer Nature. https://doi.org/10.1007/978-3-319-89920-6_52

\section{Published in:}

Operations Research Proceedings 2017

\section{Citing this paper}

Please note that where the full-text provided on Manchester Research Explorer is the Author Accepted Manuscript or Proof version this may differ from the final Published version. If citing, it is advised that you check and use the publisher's definitive version.

\section{General rights}

Copyright and moral rights for the publications made accessible in the Research Explorer are retained by the authors and/or other copyright owners and it is a condition of accessing publications that users recognise and abide by the legal requirements associated with these rights.

\section{Takedown policy}

If you believe that this document breaches copyright please refer to the University of Manchester's Takedown Procedures [http://man.ac.uk/04Y6Bo] or contact uml.scholarlycommunications@manchester.ac.uk providing relevant details, so we can investigate your claim.

\section{OPEN ACCESS}




\title{
How to control a reverse logistics system when used items return with diminishing quality
}

\author{
Imre Dobos ${ }^{1}$, Grigory Pishchulov ${ }^{2,3}$, Ralf Gössinger ${ }^{4}$ \\ ${ }^{1}$ Institute of Economic Sciences, Budapest University of Technology and Economics, \\ Hungary, dobos@kgt.bme.hu \\ ${ }^{2}$ Alliance Manchester Business School, The University of Manchester, Manchester, UK \\ ${ }^{3}$ St. Petersburg State University, 7/9 Universitetskaya nab., St. Petersburg, 199034 Russia \\ ${ }^{4}$ Dept. of Production Management and Logistics, University of Dortmund, Germany
}

\begin{abstract}
We study an integrated production-inventory system that manufactures new items of a certain product and receives some of the used items back. These can be either remanufactured on the same production line or disposed of. Used items awaiting remanufacturing need to be held in stock. New and as-good-as-new items are kept in stock, from which the product demand is satisfied. Controlling such a system involves decisions with regard to disposal of used items, succession of manufacturing and remanufacturing operations, and the choice of respective lot sizes. Recent works have referred to settings assuming variation in quality of returned items and a limited number of remanufacturing cycles that an item can undergo. We seek to determine optimal lot sizing for such a system and derive sufficient conditions for an optimal policy to forego remanufacturing.
\end{abstract}

\section{Introduction}

We study an integrated production-inventory system that manufactures new items of a particular product and receives some of the used items back after a period of use. These can be either remanufactured on the same production line or disposed of. Used items awaiting remanufacturing need to be held in stock. Both manufacturing and remanufacturing operations require setting up accordingly the production equipment. Remanufactured items are considered to be as good as new and can serve the product demand on a par with the new ones. New and as-good-asnew items are kept in stock, from which the product demand is satisfied.

Controlling such a system involves decisions with regard to disposal of used items, succession of manufacturing and remanufacturing operations, and the choice of respective lot sizes. Existing research has studied control policies for such production-inventory systems in a variety of different settings. Specifically, beginning with the work of Schrady [5] and Richter [4], significant attention has been devoted to settings assuming deterministic constant demand and return rates. 
A more recent work has referred to settings assuming variation in quality of returned items [1] as well as a limited number of remanufacturing cycles that an item can undergo due to wear and tear [3]. We extend this line of research by studying a setting in which used items return in a condition that depends on the number of remanufacturing cycles an item underwent and determines the inventory holding costs of that item. We determine optimal lot sizing for such a system and derive sufficient conditions for an optimal policy to forego remanufacturing.

The paper is organized as follows. Section 2 presents the model and the optimal total lot size. Section 3 gives sufficient optimality conditions. Section 4 concludes.

\section{The model and the optimal solution for the total lot size}

Consider a production-inventory system with two shops. The first shop is capable of producing new items of a certain product and also remanufacturing used items, which are then considered as good as new. Both kinds of items are used to satisfy market demand. They return after a period of use and are either disposed of or accumulated in the second shop during the collection interval $[0, \mathrm{~T}]$, at the end of which these items are shipped to the first shop. The shipment time is constant and normalized to zero. The collection interval thus determines the length of a manufacturing-remanufacturing cycle in the first shop. A cycle begins with remanufacturing used items, if any. The latter are distinct w.r.t. the number of times $i$ they have been remanufactured already before and are respectively called type-i items (Fig. 1). We assume that remanufacturing proceeds in the order of increasing type index $i$. We seek to minimize time-average system costs over an infinite horizon.

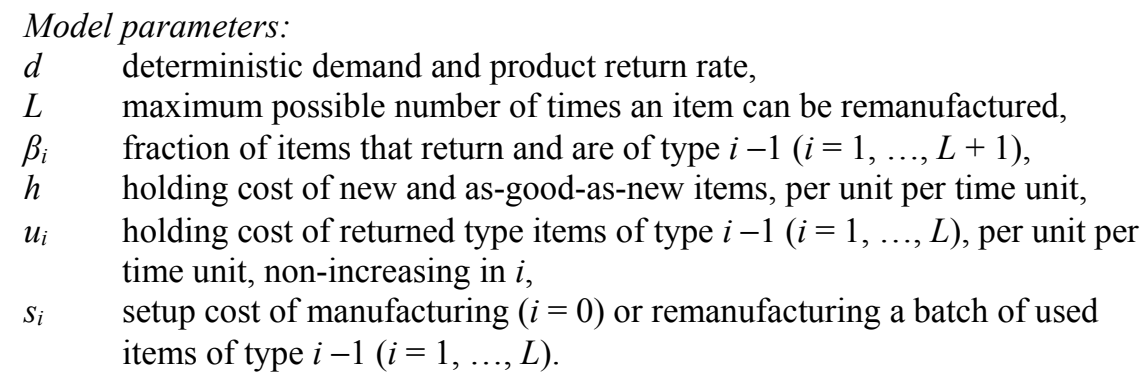
time unit, non-increasing in $i$,

$s_{i} \quad$ setup cost of manufacturing $(i=0)$ or remanufacturing a batch of used items of type $i-1(i=1, \ldots, L)$.

\section{Decision variables:}

$l \quad$ how many times to remanufacture used times, $l \leq L$,

$T$ length of the manufacturing-remanufacturing cycle,

$q_{0}(l)$ manufacturing lot size, positive,

$q_{i} \quad$ remanufacturing lot size of used items of type $i-1(i=1, \ldots, l)$,

$n_{0}(l)$ number of manufacturing lots, positive integer,

$n_{i} \quad$ number of remanufacturing lots of type $i-1(i=1, \ldots, l)$, positive,

$x \quad$ total lot size of the new and as-good-as-new products, $x=d \cdot T$, positive,

$\beta_{0}(l)$ fraction of returned items that are disposed of. 
Fig. 1. Material flow when returned items of types above $l$ are disposed of.

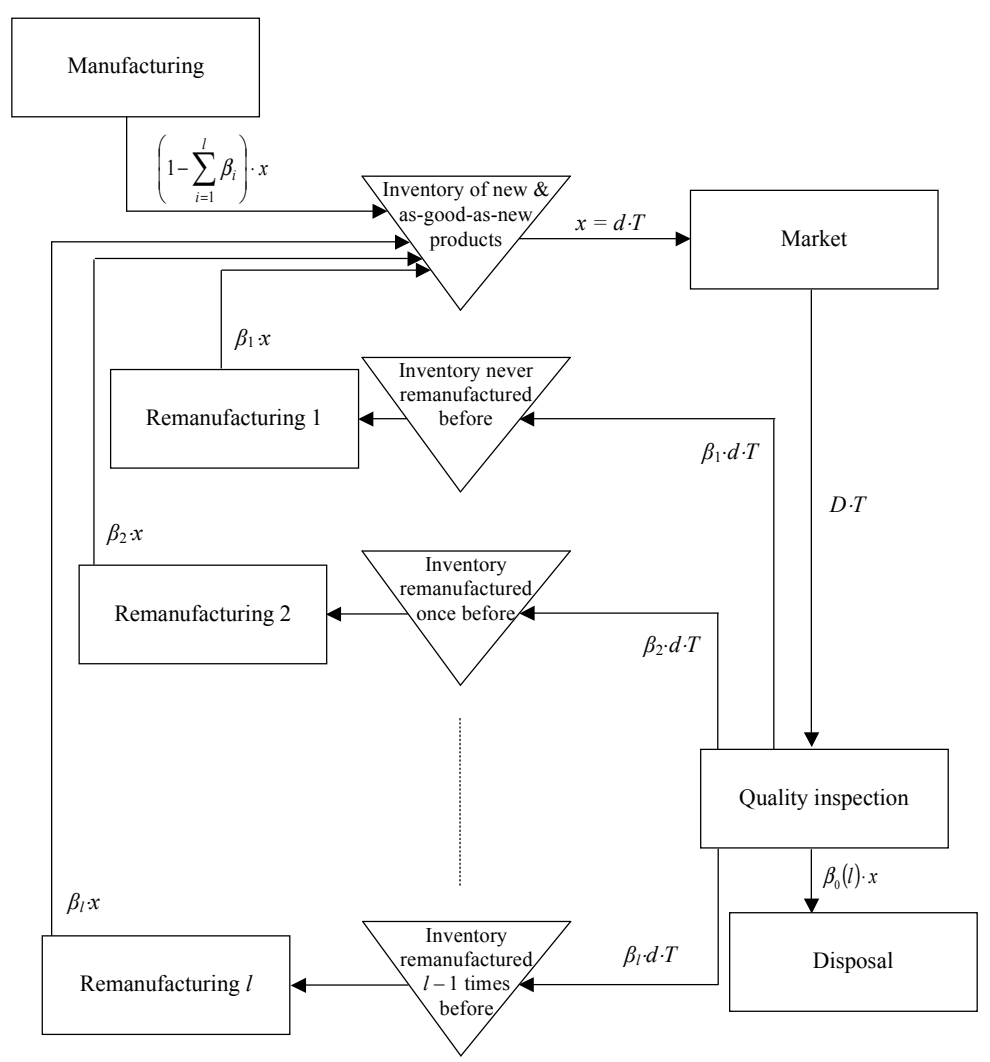

It holds for the respective fractions of returned items that $\beta_{0}(l)+\sum_{i=1}^{l} \beta_{i}=1$.

Note that type- $L$ items are disposed of due to wear and tear, while any other items are disposed of for economic reasons. Manufacturing and remanufacturing volumes within a cycle are then, respectively:

$n_{0}(l) \cdot q_{0}(l)=\left(1-\sum_{i=1}^{l} \beta_{i}\right) \cdot x \quad$ and $\quad n_{i} \cdot q_{i}=\beta_{i} \cdot x \quad(i=1, \ldots, l)$

Average total costs per time unit can be expressed as (Dobos and Richter [2]):

$$
A C\left(l,\left\{n_{i}\right\}_{i=0}^{l}, x\right)=\left[\frac{d}{x} s_{0} n_{0}(l)+\frac{x}{2} h \frac{\beta_{0}(l)^{2}}{n_{0}(l)}\right]+\sum_{i=1}^{l}\left\{\frac{d}{x} s_{i} n_{i}+\frac{x}{2}\left[\left(h-u_{i}\right) \frac{\beta_{i}^{2}}{n_{i}}+u_{i}\left(\beta_{i}+\beta_{i}^{2}\right)\right]\right\}
$$

where the first bracketed expression represents the setup and holding costs associated with manufacturing new items, and the expression in the curly braces represents the respective costs associated with the items of type $i-1$. 
Assume for now that $\beta_{i}>0$ holds for all $i=1, \ldots, l$. By expressing the lot sizes $\left\{q_{i}\right\}_{i=0}^{l}$ from (1) and substituting these into (2), we get:

$A C\left(l,\left\{q_{i}\right\}_{i=0}^{l}, x\right)=\beta_{0}(l)\left(s_{0} \frac{d}{q_{0}}+h \frac{q_{0}}{2}\right)+\sum_{i=1}^{l} \beta_{i}\left[s_{i} \frac{d}{q_{i}}+\left(h-u_{i}\right) \frac{q_{i}}{2}+\frac{x}{2} u_{i}\left(1+\beta_{i}\right)\right]$

where the numbers of lots have to satisfy: $n_{0}(l)=x \beta_{0}(l) / q_{0} \geq 1, n_{i}=x \beta_{i} / q_{i} \geq 1$ $(i=1, \ldots, l)$. Given a total lot size $x$, the optimal lot sizes can be derived from (3):

$q_{0}(l, x)=\min \left\{x \beta_{0}(l), \sqrt{\frac{2 s_{0} d}{h}}\right\}, \quad q_{i}(x)=\min \left\{x \beta_{i}, \sqrt{\frac{2 s_{i} d}{h-u_{i}}}\right\} \quad(i=1, \ldots, l)$.

It can be shown that $q_{0}(l, x) \geq q_{0}(l+1, x)$, i.e. the manufacturing lot sizes are declining in the remanufacturing limit $l$. Substituting the lot sizes into (3) gives:

$$
A C^{\prime}(l, x)=\beta_{0}(l)\left[s_{0} \frac{d}{q_{0}(l, x)}+\frac{h}{2} q_{0}(l, x)\right]+\sum_{i=1}^{l}\left\{\beta_{i}\left[s_{i} \frac{d}{q_{i}(x)}+\frac{h-u_{i}}{2} q_{i}(x)\right]+x \frac{u_{i}}{2}\left(\beta_{i}+\beta_{i}^{2}\right)\right\}
$$

Define $u_{0}=0$, and let

$$
x_{1}=\frac{1}{1-\sum_{i=1}^{l} \beta_{i}} \sqrt{\frac{2 s_{0} d}{h-u_{0}}}=\frac{1}{\beta_{0}(l)} \sqrt{\frac{2 s_{0} d}{h}}, \quad x_{i+1}=\frac{1}{\beta_{i}} \sqrt{\frac{2 s_{i} d}{h-u_{i}}} \quad(i=1, \ldots, l) .
$$

The value $x_{i-1}$ represents the total lot size that optimizes the type- $i$ lot size. Let $x_{i}$ $(i=1, \ldots, l+1)$ be arranged in a non-decreasing order: $0<x_{i_{1}} \leq \ldots \leq x_{i_{l+1}}$. Then

$$
A C^{\prime}(l, x)= \begin{cases}\sum_{j=1}^{l+1}\left(\frac{s_{i_{j}} d}{x}+\frac{h \beta_{i_{j}}^{2}+u_{i_{j}} \beta_{i_{j}}}{2} x\right) & 0<x<x_{i_{1}} \\ \ldots & \ldots \\ \sum_{j=1}^{k-1}\left[\beta_{i_{j}} \sqrt{2 d s_{i_{j}}\left(h-u_{i_{j}}\right)}+x \frac{u_{i_{j}}}{2}\left(\beta_{i_{j}}+\beta_{i_{j}}^{2}\right)\right]+\sum_{j=k}^{l+1}\left(\frac{s_{i_{j}} d}{x}+\frac{h \beta_{i_{j}}^{2}+u_{i_{j}} \beta_{i_{j}}}{2} x\right) & x_{i_{k-1}} \leq x<x_{i_{k}} \\ \ldots & \ldots \\ \sum_{j=1}^{l+1}\left[\beta_{i_{j}} \sqrt{2 d s_{i_{j}}\left(h-u_{i_{j}}\right)}+x \frac{u_{i_{j}}}{2}\left(\beta_{i_{j}}+\beta_{i_{j}}^{2}\right)\right] & x_{i_{l+1}} \leq x\end{cases}
$$

$A C^{\prime}(l, x)$ is convex and continuously differentiable in $x$. Thus for a given $l$, the optimal total lot size $x^{l}$ satisfies $d A C^{\prime}\left(l, x^{l}\right) / d x=0$. Define $x_{i_{0}}=0$. Then it holds that 
$x^{l}=\sqrt{\frac{2 d \sum_{j=k^{\circ}}^{l+1} s_{i_{j}}}{\sum_{j=1}^{k^{\circ}-1} u_{i_{j}}\left(\beta_{i_{j}}+\beta_{i_{j}}^{2}\right)+\sum_{j=k^{\circ}}^{l+1}\left(h \beta_{i_{j}}^{2}+u_{i_{j}} \beta_{i_{j}}\right)}} \quad$ and $\quad x_{i_{k^{\circ}-1}} \leq x^{l}<x_{i_{k^{\circ}}}$

for some $k^{\circ} \in\{1, \ldots, l+1\}$ that can be easily determined by evaluating the sign of the derivative $d A C^{\prime}(l, x) / d x$ at the boundary points $x_{i_{k}}$ for $k=1, \ldots, l+1$. The minimal average total costs for the given $l$ are accordingly found to be

$$
A C^{\prime}\left(l, x^{l}\right)=\sum_{j=1}^{k^{\circ}-1} \beta_{i_{j}} \sqrt{2 d s_{i_{j}}\left(h-u_{i_{j}}\right)}+\sqrt{2 d\left(\sum_{j=k^{\circ}}^{l+1} s_{i_{j}}\right)\left[\sum_{j=1}^{k^{\circ}-1} u_{i_{j}}\left(\beta_{i_{j}}+\beta_{i_{j}}^{2}\right)+\sum_{j=k^{\circ}}^{l+1}\left(h \beta_{i_{j}}^{2}+u_{i_{j}} \beta_{i_{j}}\right)\right]} .
$$

The above results can now be easily extended to the case of any $\beta_{i}=0$ by excluding the respective type from (3) and all subsequent expressions. Below we address the problem of determining an optimal $l^{o}=\arg \min _{0 \leq \leq \leq L} A C^{\prime}\left(l, x^{l}\right)$.

\section{A type of optimal solutions: No remanufacturing}

In this section we are looking for sufficient optimality conditions of a policy that excludes any remanufacturing. It is easy to see that the following trivially holds:

$$
A C^{\prime}\left(l+1, x^{l+1}\right)-A C^{\prime}\left(l, x^{l}\right) \geq A C^{\prime}\left(l+1, x^{l+1}\right)-A C^{\prime}\left(l, x^{l+1}\right) \quad(l=0, \ldots, L-1) .
$$

If the right-hand side in (4) is nonnegative then $A C^{\prime}\left(l, x^{l}\right) \leq A C^{\prime}\left(l+1, x^{l+1}\right)$ holds for all $l=0, \ldots, L-1$, and hence an optimal solution excludes remanufacturing.

It can be shown that the right-hand side in (4) can be rewritten as $A C_{1}(l+1)-A C_{0}(l)$, where $A C_{0}(l)=\beta_{0}(l)\left(s_{0} d / q_{0}\left(l, x^{l+1}\right)+h q_{0}\left(l, x^{l+1}\right) / 2\right)$,

$$
A C_{1}(l+1)= \begin{cases}\left.\sqrt{2 d\left(s_{0}+s_{l+1}\right)\left\{h\left[\beta_{0}(l)-\beta_{l+1}\right]^{2}+h \beta_{l+1}^{2}+u_{l+1} \beta_{l+1}\right.}\right\} & x<\min \left(x_{0} ; x_{l+1}\right) \\ \left.\left[\beta_{0}(l)-\beta_{l+1}\right] \sqrt{2 s_{0} d h}+\sqrt{2 d s_{l+1}\left(h \beta_{l+1}^{2}+u_{l+1} \beta_{l+1}\right.}\right) & x_{0} \leq x<x_{l+1} \\ \beta_{l+1} \sqrt{2 s_{l+1} d\left(h-u_{l+1}\right)}+\sqrt{2 d s_{0}\left\{h\left[\beta_{0}(l)-\beta_{l+1}\right]^{2}+u_{l+1}\left(\beta_{l+1}^{2}+\beta_{l+1}\right)\right\}} & x_{l+1} \leq x<x_{0}\end{cases}
$$

and $x, x_{0}, x_{l+1}$ are suitably chosen lot sizes whose closed-form expressions are omitted for reasons of space and available from the authors on request.

It is easy to see that $A C_{1}(l+1)$ converges to $A C_{0}(l)$ as $\beta_{l+1}$ approaches zero. Now defining $K^{l}\left(\beta_{l+1}\right):=A C_{1}(l+1)$, we can immediately use Lemma 1 by Dobos and Richter [2], which yields the following result. 
Lemma 1. $K^{l}\left(\beta_{l+1}\right)$ can be computed as follows:

(i) $s_{l+1} h\left[\beta_{0}(l)-\beta_{l+1}\right]^{2} \geq s_{0}\left(h \beta_{l+1}^{2}+u_{l+1} \beta_{l+1}\right) \Rightarrow$ $\left.K^{l}\left(\beta_{l+1}\right)=\beta_{l+1} \sqrt{2 s_{l+1} d\left(h-u_{l+1}\right)}+\sqrt{2 d s_{0}\left\{h\left[\beta_{0}(l)-\beta_{l+1}\right]^{2}+u_{l+1}\left(\beta_{l+1}^{2}+\beta_{l+1}\right)\right.}\right\}$

(ii) $s_{l+1} h\left[\beta_{0}(l)-\beta_{l+1}\right]^{2}-s_{0} u_{l+1} \beta_{l+1}\left(1+\beta_{l+1}\right) \leq s_{0}\left(h-u_{l+1}\right) \beta_{l+1}^{2} \leq$

$\leq s_{l+1}\left\{h\left[\beta_{0}(l)-\beta_{l+1}\right]^{2}+u_{l+1} \beta_{l+1}\left(1+\beta_{l+1}\right)\right\} \Rightarrow$

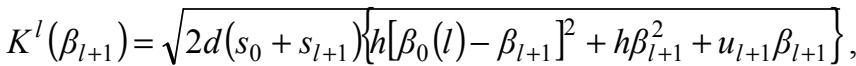

(iii) $s_{l+1}\left(h-u_{l+1}\right) \beta_{l+1}^{2} \geq s_{l+1}\left\{h\left[\beta_{0}(l)-\beta_{l+1}\right]^{2}+u_{l+1} \beta_{l+1}\left(1+\beta_{l+1}\right)\right\} \Rightarrow$

$\left.K^{l}\left(\beta_{l+1}\right)=\beta_{l+1} \sqrt{2 s_{l+1} d\left(h-u_{l+1}\right)}+\sqrt{2 d s_{0}\left\{h\left[\beta_{0}(l)-\beta_{l+1}\right]^{2}+u_{l+1}\left(\beta_{l+1}^{2}+\beta_{l+1}\right)\right.}\right\}$.

Using Lemma 1, we can evaluate $A C_{1}(l+1)$ and thus the right-hand side in (4). If the latter is nonnegative for all $l$ then it is optimal to forego remanufacturing.

Further observe that disposing of all returns of type $l$ is equivalent to enforcing $\beta_{l+1}=0$ in our model. Below we obtain a sufficient optimality condition for abandoning remanufacturing regardless of the specific return fractions. To this end, we let $\beta_{l+1}$ vary within the range $[0,1]$, and refer to the concept of a convex envelope function $\widetilde{K}^{l}\left(\beta_{l+1}\right)$ for $K^{l}\left(\beta_{l+1}\right)$ (see Fig. 2 for an illustration).

Fig. 2. Convex envelope $\widetilde{K}^{l}\left(\beta_{l+1}\right)$ of function $K^{l}\left(\beta_{l+1}\right)$.

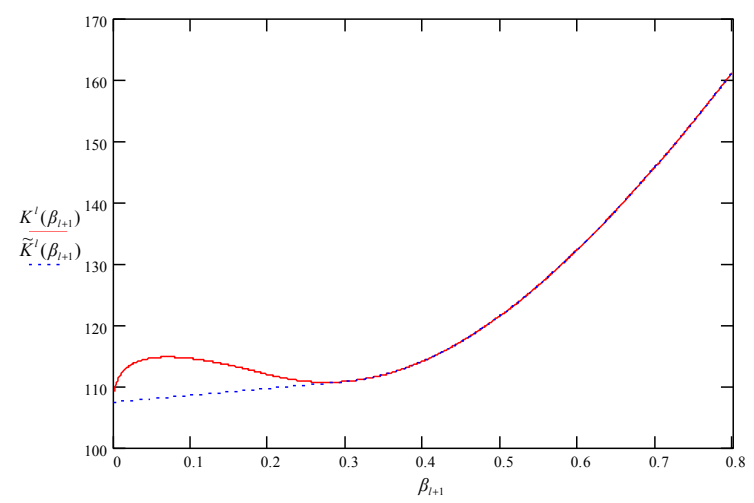

Lemma 2. If the convex envelope functions $\widetilde{K}^{l}\left(\beta_{l+1}\right)$ are monotone increasing for $l=0, \ldots, L-1$ then it is optimal not to remanufacture given any return fractions $\beta_{l+1}(l=0, \ldots, L)$.

The proof is obvious because $A C^{\prime}\left(l+1, x^{l+1}\right)-A C^{\prime}\left(l, x^{l+1}\right) \geq 0$ proves to hold true for all $\beta_{l+1}$ and $l=0, \ldots, L-1$, which implies optimality of disposing of type- $l$ items, while type- $L$ items are disposed of due to wear and tear. Of course, if the convex envelopes have minimum points then it can be optimal to remanufacture. 


\section{Conclusion}

We have investigated a manufacturing-remanufacturing model with quality considerations. The goal of the decision maker is to minimize the relevant EOQ related costs, and to choose an optimal number of remanufacturing cycles. We have examined a special case when remanufacturing is not optimal and obtained sufficient conditions for that.

A further study could address settings where the decision maker acquires used items depending on the number of remanufacturing cycles they have undergone. Another extension could be the search for an optimal policy in case of variable return rates.

Acknowledgments The first author gratefully acknowledges financial support by the Gambrinus Fellowship Programme during his research stay at the University of Dortmund, Germany in 2016-2017. The second author gratefully acknowledges financial support by the same university.

\section{References}

1. Dobos, I., Richter, K.: A production/recycling model with quality considerations. International Journal of Production Economics 104, 571-579 (2006)

2. Dobos, I., Richter, K.: The Integer EOQ Repair and Waste Disposal Model: A Further Analysis. Central European Journal of Operations Research 8, 174-193 (2000)

3. El Saadany, A.M.A., Jaber, M.Y., Bonney, M.: How many times to remanufacture? International Journal of Production Economics 143, 598-604 (2013)

4. Richter, K.: The EOQ repair and waste disposal model with variable setup numbers. European Journal of Operational Research 96, 313-324 (1996)

5. Schrady, D.A.: A deterministic inventory model for repairable items. Naval Research Logistics Quarterly 14, 391-398 (1967) 